\section{Amitriptyline-induced anorgasmia reversed by nefazodone}

Sir - Delayed or absent ejaculation and/or orgasm is the commonest sexual side-effect of antidepressant drugs, matched only by decreased libido. Attempts to treat antidepressant-induced anorgasmia with cyproheptadine, amantadine, methylphenidate, yohimbine, dosage reduction, drug holidays and drug substitution had mixed results.' We report a case of amitriptyline-induced anorgasmia reversed by switching over to nefazodone.

A 31 year old married man was referred with a first episode of major depression of six months duration. Prior to the onset of depression he was sexually active. He had decreased libido and decreased frequency of sexual intercourse since the onset of the depression. His depression as well as his libido improved on treatment with amitriptyline $200 \mathrm{mg}$ for four weeks. However, he was unable to attain ejaculation/orgasm even after trying for 30 minutes and caused his wife genital soreness. This increased the strain on their marriage which was already affected by his depression. Therefore we stopped the amitriptyline and commenced him on nefazodone. Six weeks after being on nefazodone $400 \mathrm{mg} /$ day, he reported complete return of normal sexual functioning while his depression remained in remission.

This is the first report of successful reversal of antidepressant-induced anorgasmia by substitution with nefazodone. Nefazodone inhibits serotonin reuptake and blocks $5-\mathrm{HT}_{2}$ receptors, resulting in the facilitation of 5$\mathrm{HT}_{\text {IA }}$ neurotransmission. Both $5-\mathrm{HT}_{2}$ blockers ${ }^{1}$ and $5-\mathrm{HT}_{1 \mathrm{~A}}$ agonists ${ }^{2}$ facilitate male rat sexual behaviour. This may explain the reports of nefazodone causing spontaneous ejaculations ${ }^{3}$ and correcting sertraline-induced anorgasmia when used as an adjunct.'

All antidepressant drugs have the potential to cause sexual side-effects which can cause distress, impair quality of life and reduce compliance with treatment. An adverse effect in one patient may be used beneficially in another.

Ranga Rao, MBBS, DPM, MD, DipNBE, MRCPsych, Consultant and Senior Lecturer in Psychiatry, Ladywell Mental Health Unit, University Hospital of Lewisham, Lewisham SE13 6LH, England.

Richard K Morriss, MB, BCh, MMedSc, MD, MRCPsych, Senior Lecturer \& Hon Consultant Psychiatrist, Royal Preston Hospital, Preston PR2 4HT, England.

Albert Michael, MBBS, DPM, MD, MRCPsych, Consultant Psychiatrist, West Suffolk Hospital, Bury St. Eainunds, IP33 2QZ,

England.

References

1. Reynolds RD. Sertraline-induced anorgasmia treated with intermittent nefazodone. J Clin Psychiatry 1997; 58: 89

2. Pfaus JG, Everitt BJ. The pharmacology of sexual behaviour. In Psychopharmacology: The Fourth Generation of Progress. Bloom FE, Kupfer Psychopharmacology: The Fourth Generation of

3. Michael A, Ramana R. Nefazodone-induced spontaneous ejaculation. Br Psychiatry 1996; 169: 672-3.

\section{Extrapyramidal reactions from concurrent SSRI and atypical antipsychotic use}

Sir - In a recent letter, Farragher and Walsh' report what they believe is a delayed onset of extrapyramidal sideeffects in a patient concurrently receiving paroxetine and risperidone. In their letter they explain that their patient had a diagnosis of paranoid schizophrenia, had received at least three antipsychotics (separately) prior to receiving risperidone, and had never experienced an extrapyramidal reaction. Further, this 45 year old man had safely taken risperidone up to $6 \mathrm{mg} / \mathrm{day}$ for a duration of one year and had also initially tolerated the eventual addition of paroxetine $20 \mathrm{mg} /$ day to risperidone $4 \mathrm{mg} /$ day for a total of 18 days. This patient then presented 48 days post-discharge with bucco-facial rigidity and involuntary movements of the same area. The authors essentially conclude by attributing this extrapyramidal reaction to paroxetine. I believe that additional points are worth raising.

First, the authors line of reasoning for determining that paroxetine was the 'likely causative factor' of this patient's delayed EPR is incomplete. In their letter, Farragher and Walsh contend that because their patient had tolerated higher previous risperidone doses for one year, that risperidone could not have played a role. Further, because their patient was able to tolerate this higher dose of risperidone previously, the authors rule out the possibility that a pharmacokinetic drug-drug interaction between paroxetine and risperidone may have contributed to this patient's EPR. The extrapolation here would be that paroxetine, through its inhibition of the CYP-450 2D6 isoenzyme, may elevate plasma risperidone levels which would in turn mimic a higher dose of risperidone.

In considering the cause of this EPR, we should not lose sight of the fact that risperidone is a potent $D_{2}$ receptor antagonist ${ }^{2,3}$ and that because the patient was taking the risperidone, that some degree of $\mathrm{D}_{2}$ antagonism was occurring because of this drug. In addition to possibly raising plasma risperidone levels, paroxetine may have been causing an indirect inhibition of dopaminergic activity, ${ }^{4}$ this may manifest in some patients as an EPR. The concurrent pharmacodynamics of risperidone and paroxetine (with or without the said pharmacokinetic interaction) was not proposed in the letter by Farragher and Walsh. The only way that paroxetine could have been assessed to be the sole cause of this patient's EPR is if paroxetine was readministered alone and the same reaction occurred. It is therefore reasonable to assert that this reaction could not have occurred without the degree of $\mathrm{D}_{2}$ receptor antagonism being exerted by the risperidone.

Second, the above presumes that the patient was diligent in following his prescribed dosing regimen. Farragher and Walsh do not address the reliability of their patient to remain compliant with the prescribed pharmacotherapy. Non-compliance being a realistic concern for any pharmacotherapeutic regimen, it is certainly plausible to consider that their patient was not reliably taking either or both medications as prescribed. Given this, we do not truly know whether the reported EPR was in fact due to paroxetine, risperidone, both, or neither.

A final comment involves the extent to which extra- 
pyramidal reactions (EPRs) have been reported in the literature. Overall, there at least 28 reports involving a minimum of 42 patients who have experienced an EPR associated with an SSRI. ${ }^{5}$ In this body of literature, a full range of EPRs have been reported including what appears to be a reversible (tardive-like) dyskinesia. Important risk factors for developing EPRs after starting an SSRI may include concurrent antipsychotic use, using a rapid SSRI dose escalation strategy, treating with high daily SSRI doses, older patients, female patients and patients with PD. Unfortunately, because the available information is largely from anecdotal reports, definitive risk factor guidelines are unavailable.

From cases like the one published by Farragher and Walsh, it has become clear that there is a real possibility that patients being treated with an SSRI may experience EPRs. The true risk of SSRI-related EPRs and the associated risk factors, however, are presently unclear. One potential risk factor may include the concurrent use of an antipsychotic (including an atypical antipsychotic). If an EPR develops while a patient is receiving both an SSRI and an antipsychotic, it is important to realise that there is a potential pharmacodynamic interaction which may occur in addition to a pharmacokinetic interaction.

\section{Charles F Caley, PharmD, BCPP, Assistant Clinical Professor of Pharmacy, University of Connecticut - School of Pharmacy and Psychopharmacology Consultant, The Institute of Living - Burlingame Center for Psychiatric Research and Education, 400 Washington Street, Hartford, CT 06106-3392,} USA

\section{References}

1. Farragher B, Walsh N. Delayed extrapyramidal side-effect on combining paroxetine and risperidone [letter]. Ir J Psych Med 1997; 14: 117.

2. Leysen JE, Gommeren W, Eens A et al. Biochemical profile of risperidone, a new antipsychotic. J Pharmacol Exp Ther 1988; 247: 661-70.

3. Bymaster FP, Calligaro DO, Falcone JF et al. Radioreceptor binding profile of the atypical antipsychotic olanazapine. Neuropsychopharmacology 1996; 14 $87-96$

4. Baldessarini RJ, Marsh E. Fluoxetine and side-effects (letter). Arch Gen Psychiatry 1990; 47: 191-2.

5. Caley CF. Extrapyramidal reactions and the selective serotonin reuptake inhibitors. Ann Pharmacother 1997, in print.

\section{Re: Diogenes syndrome: review and case history}

Sir - O'Shea and Falvey report a case of Diogenes Syndrome and in reviewing the literature in the area emphasise the interplay of factors contributory to the presentation, including organic brain disease, psychotic illness, and personality (Ir J Psych Med 1997; 14(3): 1156).' We report a case of a 50 year old female patient in which all three factors appeared to contribute to the classic presentation and discuss implications for investigation of the purported syndrome.

A 50 year old woman was admitted to a psychiatric ward in an advanced state of self-neglect. This retired single nurse had a 20 year history of contact with the psychiatric services, initially for peer relationship problems, subsequently being admitted twice for treatment of depressive episodes. Medical history included menorrhagia, hypothyroidism and scoliosis. In the period prior to admission she had stopped all of her regular medication and allowed her home to become extremely dirty. She ate very little, but her cat was well cared for. She agreed to informal admission.

Mental state and physical examination, and blood tests were normal on admission and she improved rapidly without any new treatment. Occupational therapy assessment suggested visuospatial problems, so a MRI scan was performed. This revealed a large sessile meningioma in the left middle cranial fossa, with temporo-parietal mass effect, as well as some cerebral atrophy. Neuropsychological testing showed selective frontal deficits but a high NART-IQ of 122. Spect scan was normal. She had the tumour removed and was discharged home two months later. She had a fluctuating clinical course subsequently, with at least one more admission (with persecutory delusions and self-neglect). Unconcern with her situation was striking throughout.

Our case demonstrated personality features similar to Clark et al's original series, ${ }^{2}$ including detachment and poor integration. We felt that organic brain disease had 'released' the behavioural syndrome at an early age. No association of temporo-parietal lobe lesions with neglect has been previously reported. A possible explanation is that the lesion to the parietal lobe led to unawareness of neglect, akin to anosognosia, the unawareness of disease. We feel that organic brain disease should be suspected in all cases of severe neglect, while acknowledging the potential contribution of multiple factors to the phenomenon. Ascription of her neglect to constitutional (personality) factors, or to her previous psychiatric illness, would have been an unfortunate omission.

Bart Sheehan, MRCPsych, Specialist Registrar in Old Age Psychiatry, Maudsley Hospital, Denmark Hill, London SE5 8AZ, England.

John Geddes, MD, MRCPsych, Dept of Psychiatry, University of Oxford, Warneford Hospital, Oxford OX3 7IX, England.

References

1. O'Shea B, Falvey J. Diogenes syndrome: review and case history. Ir J Psych Med 1997; 14(3): 115-6.

2. Clark ANG, Mankikar GD, Gray I. Diogenes syndrome: a clinical study of gross neglect in old age. Lancet 1975; 1: 366-8.

\section{Serious hypertensive reaction after switching from clomipramine to moclobemide}

Sir - Moclobemide is a selective, reversible inhibitor of monoamine oxidase A (MAO-A) which differs from the classical, irreversible monoamine oxidase inhibitors (MAOIs), both in pharmacodynamic and pharmacokinetic properties and has therefore a low propensity for producing drug interaction. ${ }^{1}$ Recently, in a doubleblind 